\title{
INFLUÊNCIA DE INIBIDORES NA FERMENTAÇÃO ETANÓLICA DE XILOSE POR PICHIA STIPITIS
}

\author{
A. S. SILVA ${ }^{1}$, A. M. OLIVEIRA Jr ${ }^{1}$ e A. K. S. ABUD ${ }^{1}$ \\ ${ }^{1}$ Universidade Federal de Sergipe, Departamento de Tecnologia de Alimentos \\ E-mail para contato: ana.abud@gmail.com
}

\begin{abstract}
RESUMO - A biomassa agroindustrial é uma promissora alternativa energética. Contudo, para sua conversão em açúcares, necessita de pré-tratamentos, os quais liberam não apenas hexoses, mas também pentoses e outros açúcares, além de inibidores. O efeito dos inibidores ácido acético, furfural e hidroximetilfurfural na cinética de produção de etanol pela levedura Pichia stipitis, tendo como substrato xilose comercial, é avaliado neste trabalho. As fermentações ocorreram em frascos Erlenmeyer de $250 \mathrm{~mL}$, à temperatura ambiente, $150 \mathrm{rpm}$, durante $72 \mathrm{~h}$ e sem controle de $\mathrm{pH}$, tendo a concentração inicial de $2.10^{7}$ cél $/ \mathrm{mL}$. A mistura dos inibidores influenciou negativamente o processo, não se observando crescimento celular, apesar de consumo de $30 \%$ da xilose, enquanto que a adição de $0,4 \mathrm{~g} / \mathrm{L}$ de hidroximetilfurfural se mostrou benéfica ao processo fermentativo, com conversão quase que completa da xilose à etanol e produtividade em etanol de 0,19 $\mathrm{g} / \mathrm{L} \mathrm{h}$. Apesar de crescimento semelhante ao processo sem adição de inibidores, a adição de furfural e de ácido acético gerou, após $48 \mathrm{~h}$, menor taxa de conversão de xilose em células e em etanol, com menor produtividade e taxa de crescimento celular, respectivamente.
\end{abstract}

\section{INTRODUÇÃO}

O Brasil produziu 23,54 milhões de $\mathrm{m}^{3}$ de etanol em 2012 (ANP, 2013) com base na conversão da sacarose da cana-de-açúcar, o chamado etanol de primeira geração. Neste processo, a cana-deaçúcar é esmagada e o caldo extraído, rico em sacarose, é convertido em etanol pela fermentação alcoólica. Apesar da grande produção, a demanda brasileira e mundial por combustíveis renováveis tem aumentado consideravelmente nos últimos anos, tanto por razões econômicas (alto preço dos combustíveis fósseis) quanto por questões socioambientais, devido ao fato de o etanol combustível produzido por fermentação não contribuir para o aumento líquido de dióxido de carbono $\left(\mathrm{CO}_{2}\right)$ para a atmosfera, pois é produzido por matérias-primas renováveis, as quais seqüestram o $\mathrm{CO}_{2}$ da mesma (Demirbas, 2005 citado por Cabral et al., 2009).

Para suprir a demanda de etanol, grandes esforços têm sido feitos para o desenvolvimento de processos de produção a partir de biomassas alternativas, incluindo biomassa lignocelulósica, a qual engloba resíduos agroindustriais, lixo urbano, resíduos florestais, etc, que participam em aproximadamente $50 \%$ da biomassa terrestre e somam, somente no Brasil, 350 milhões de toneladas destes resíduos por ano (Ballesteros, 2001; Pereira Jr, 2007). 


\section{9 a 22 de outubro de 2014 \\ Florianópolis/SC}

Na conversão da biomassa lignocelulósica à etanol são necessárias 5 operações unitárias. (1) Redução do tamanho da biomassa para aumentar a área superficial e uniformidade; (2) pré-tratamento para romper estrutura da lignina e da hemicelulose, reduzindo a cristalinidade da celulose e aumentando a porosidade da biomassa; (3) hidrólise enzimática para converter açúcares poliméricos em açúcares monoméricos; (4) fermentação para produzir etanol a partir dos açúcares monoméricos. (5) recuperação do etanol por destilação ou outra tecnologia de separação (García-Cubero et al., 2011).

As hemiceluloses são heteropolímeros de pentoses e hexoses e a hidrólise das hemiceluloses fornece, principalmente, pentoses, onde a xilose é o açúcar predominante, compreendendo 20 a $40 \%$ do total de carboidratos dos resíduos agrícolas (Moraes et al., 2010). Todavia, os carboidratos oriundos das pentoses (xilose e arabinose) não são diretamente fermentescíveis por leveduras industriais (Saccharomyces cerevisiae), sendo a biotransformação destas pentoses a etanol um dos desafios mais importantes a ser resolvido no âmbito científico e tecnológico (Rossell, 2008; Silva et $a l ., 2011)$. Devido a isto, outras espécies de leveduras e microrganismos geneticamente modificados têm sido analisadas para a produção de etanol, com rendimento suficiente para tornar o processo economicamente atrativo (Fugita, 2010; Almeida, 2011).

Entre os microrganismos fermentadores de pentoses, a levedura Pichia stipitis aparece como capaz de fermentar xilose e outras importantes hexoses a etanol a partir do hidrolisado da biomassa lignocelulósica, sendo condições como $\mathrm{pH}$, temperatura, oxigênio, agitação e composição do meio fatores importantes no processo de bioconversão (Sunitha et al., 1999; Nigan, 2001; Cabral, 2005; Agbogbo et al., 2008; Farias et al., 2012). A Pichia stipitis, também, não requer a adição de vitaminas para a fermentação de xilose e é capaz de utilizar uma ampla variedade de açúcares como substrato, a exemplo de glicose e celobiose (Agbogbo e Wenger, 2006 citado por García-Cubero et al., 2011).

Entretanto, a fermentação costuma ser lenta e de baixo rendimento, o que provavelmente deve estar relacionado à baixa resistência dos microrganismos a altas concentrações de etanol, além de haver a geração de vários co-produtos, tais como ácido acético e ácido lático, considerados produtos de degradação. Além destes, o ácido fórmico, o furfural, o hidroximetilfurfural e fenóis podem, também, ser produzidos durante o processo, inibindo a fermentação e afetando o rendimento de produção do etanol, devendo, assim, serem removidos ou suavizados (Fugita, 2010).

Este trabalho analisa a influência dos principais inibidores formados no pré-tratamento da biomassa lignocelulósica, ácido acético, furfural e hidroximetilfurfural, no processo de fermentação etanólica em meio rico, com a levedura Pichia stipitis, contendo xilose única fonte de carboidrato.

\section{METODOLOGIA}

\subsection{Microrganismo e inóculo}

Foi utilizada a levedura Pichia stipitis NRRL Y-7124, gentilmente cedida pela Embrapa Agroenergia. A manutenção da linhagem foi realizada a partir de repiques contínuos em meio YPX (20 g/L de extrato de levedura; $10 \mathrm{~g} / \mathrm{L}$ de peptona e $20 \mathrm{~g} / \mathrm{L}$ de xilose), sendo a cultura mantida em 


\section{9 a 22 de outubro de 2014 \\ Florianópolis/SC}

tubo inclinado contendo meio YPXA (20 g/L de extrato de levedura; $10 \mathrm{~g} / \mathrm{L}$ de peptona; $20 \mathrm{~g} / \mathrm{L}$ de xilose e $20 \mathrm{~g} / \mathrm{L}$ de ágar bacteriológico).

O meio de cultura foi composto de $20 \mathrm{~g} / \mathrm{L}$ xilose; $3 \mathrm{~g} / \mathrm{L}$ extrato de levedura; $5 \mathrm{~g} / \mathrm{L}$ peptona bacteriológica; $1 \mathrm{~g} / \mathrm{L}$ sulfato de magnésio $\left(\mathrm{MgSO}_{4}\right) ; 5 \mathrm{~g} / \mathrm{L}$ fosfato de potássio monobásico $\left(\mathrm{KH}_{2} \mathrm{PO}_{4}\right)$; $3 \mathrm{~g} / \mathrm{L}$ sulfato de amônio [( $\left.\mathrm{NH}_{4}\right)_{2} \mathrm{SO}_{4}$ ]. $\mathrm{O} \mathrm{pH}$ do foi corrigido para 4,5 e, em seguida, esterilizado em autoclave à $121^{\circ}$ e 1 atm por 15 min, sendo a xilose esterilizada em separado.

Para o preparo do inóculo, alçadas de levedura foram transferidas assepticamente para frasco Erlenmeyer de $500 \mathrm{~mL}$ contendo $250 \mathrm{~mL}$ de meio de cultura e incubado à temperatura ambiente e sob agitação de $150 \mathrm{rpm}$ por $24 \mathrm{~h}$ (fase exponencial de crescimento). Depois deste tempo, foi realizada a contagem de células em câmara de Neubauer para determinar o volume necessário para inocular $2.10^{7}$ cél/mL. Com o volume definido, as células foram recuperadas por centrifugação a $3750 \mathrm{rpm}$ e $10 \mathrm{~min}$, sendo posteriormente ressuspensas no meio de fermentação.

\subsection{Processo fermentativo}

Para os testes fermentativos foi utilizado o meio contendo $20 \mathrm{~g} / \mathrm{L}$ xilose; $3 \mathrm{~g} / \mathrm{L}$ extrato de levedura; $5 \mathrm{~g} / \mathrm{L}$ peptona bacteriológica; $1 \mathrm{~g} / \mathrm{L}$ sulfato de magnésio $\left(\mathrm{MgSO}_{4}\right) ; 5 \mathrm{~g} / \mathrm{L}$ fosfato de potássio monobásico $\left(\mathrm{KH}_{2} \mathrm{PO}_{4}\right) ; 3 \mathrm{~g} / \mathrm{L}$ sulfato de amônio [( $\left.\left.\mathrm{NH}_{4}\right)_{2} \mathrm{SO}_{4}\right]$. Para o teste de inibição foram adicionadas quantidades determinadas dos inibidores ácido acético $(1,75 \mathrm{~g} / \mathrm{L})$, furfural $(1,25 \mathrm{~g} / \mathrm{L}) \mathrm{e}$ hidroximetil furfural $(0,40 \mathrm{~g} / \mathrm{L})$. $\mathrm{O} \mathrm{pH}$ do meio foi ajustado para 4,5, com solução de ácido sulfúrico 1,5 M ou hidróxido de sódio $2 \mathrm{M}$. Os experimentos foram conduzidos frascos Erlenmeyer de $250 \mathrm{~mL}$ contendo $100 \mathrm{~mL}$ de meio de cultivo, à temperatura ambiente e $150 \mathrm{rpm}$ por $72 \mathrm{~h}$, sem controle de $\mathrm{pH}$ e em condições microaeróbias (frascos fechados com tampão de algodão). Durante os experimentos, amostras foram retiradas a cada $24 \mathrm{~h}$ para determinação do crescimento celular, consumo de xilose e produção de etanol. As fermentações sem adição de inibidores (controle) e mistura foram realizadas em triplicata, enquanto que as de adição de inibidores isoladamente, em duplicata.

\subsection{Determinações analíticas}

O acompanhamento do crescimento celular foi feito através da medida de absorbância a 600 $\mathrm{nm}$, tendo água destilada como branco. Os valores de concentração foram calculados através de equação de curva de calibração entre o peso e a absorbância. A concentração de xilose foi determinada pelo método colorimétrico do ácido 3,5-dinitrossalicílico (DNS), após fervura por 5 min e leitura em espectrofotômetro a $540 \mathrm{~nm}$, de acordo com metodologia proposta por Miller (1959), tendo como curva padrão soluções de concentração conhecida de xilose. A concentração de etanol foi determinada por cromatografia gasosa, em detector de ionização de chama (FID), com coluna Restek RT-Q-Bond, isoterma a $150^{\circ} \mathrm{C}$, injeção split $60 \mathrm{~mL} / \mathrm{min}$, temperatura do injetor e do detetor a $250^{\circ} \mathrm{C}$ e tempo de análise de $3 \mathrm{~min}$. As medidas foram realizadas em triplicata.

Para avaliar a influência da inibição da levedura em estudo pela presença dos inibidores, foram calculados o rendimento em etanol ( $\left.\mathrm{Y}_{\mathrm{P} / \mathrm{S}}, \mathrm{g} / \mathrm{g}\right)$, definido pela razão entre a concentração de etanol $(\mathrm{g} / \mathrm{L})$ e a xilose consumida $(\mathrm{g} / \mathrm{L})$, a conversão de substrato em células $\left(\mathrm{Y}_{\mathrm{X} / \mathrm{S}}, \mathrm{g} / \mathrm{g}\right)$, como a razão entre 
a variação do crescimento celular e a xilose consumida, a produtividade em etanol (QP, g/L.h), pela razão entre a variação máxima da concentração de etanol $(\mathrm{g} / \mathrm{L})$ e o tempo desta fermentação

\section{RESULTADOS E DISCUSSÃO}

Para entender o comportamento da levedura frente à presença dos principais inibidores do prétratamento da biomassa lignocelulósica, do qual se extrai a hemicelulose, foram realizados estudos de fermentação em xilose comercial na ausência, na mistura e na presença de cada inibidor, cuja concentração foi definida com base em experimentos conduzidos por García-Cubero et al. (2011).

Os perfis das cinéticas de fermentação são apresentados na Figura 1. Pode-se observar que a Pichia stipitis se mostrou capaz de crescer na presença isolada destes inibidores, sendo a adição do hidroximetilfurfural (HMF), na quantidade em estudo $(0,4 \mathrm{~g} / \mathrm{L})$, benéfica para o processo fermentativo, com maior crescimento celular, consumo de substrato em $48 \mathrm{~h}$ de fermentação e produção máxima de etanol. A mistura dos inibidores influenciou significativamente o processo fermentativo, não apresentando crescimento celular e formação de etanol, apesar do lento consumo de $30 \%$ da xilose inicial nas primeiras $48 \mathrm{~h}$ de fermentação.
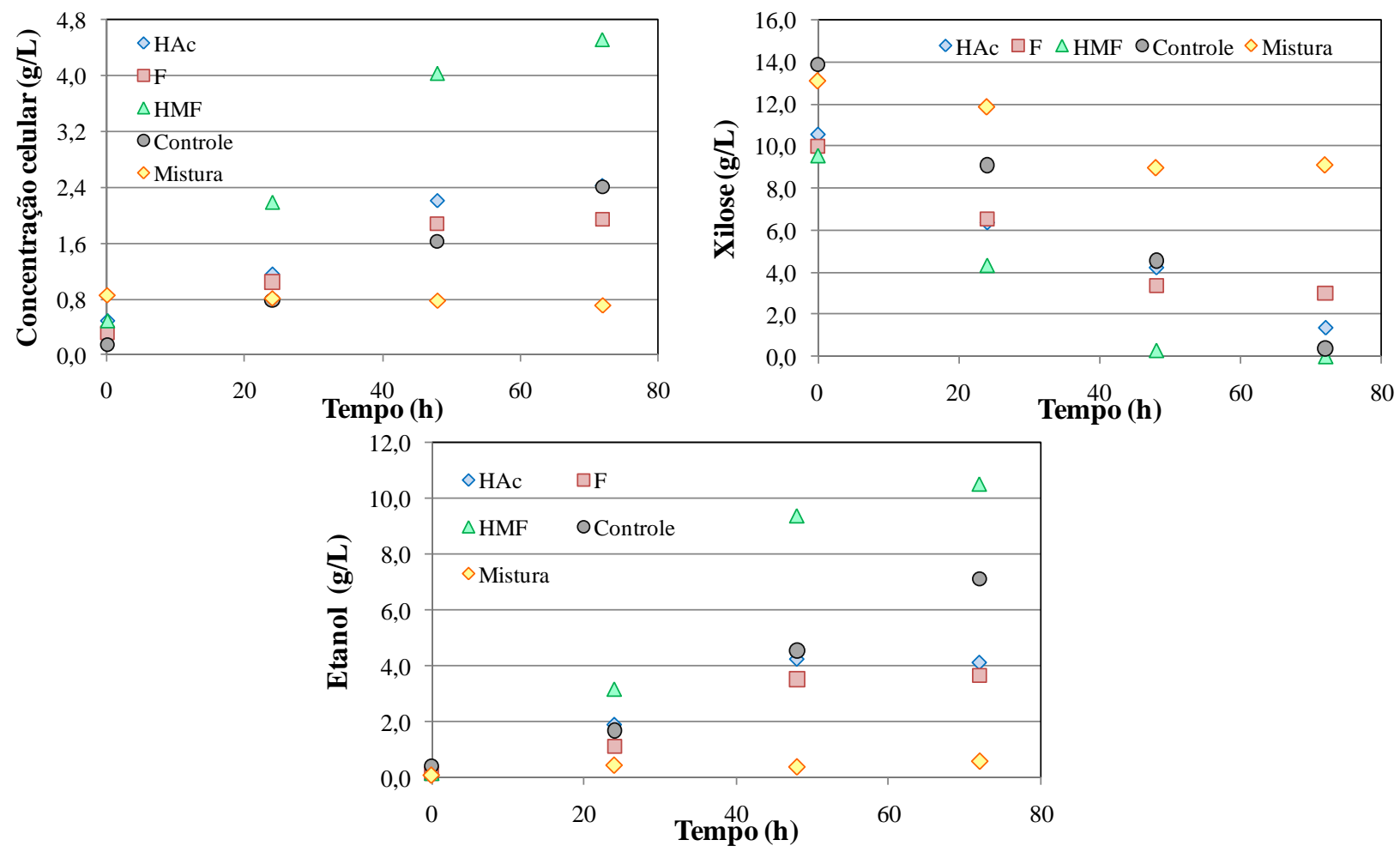

Figura 1 - Comportamento cinético das variáveis de fermentação.

Apesar de crescimento semelhante ao processo sem adição de inibidores (controle), a adição de furfural (F) e de ácido acético (HAc) gerou, após 48 h, menor taxa de conversão de substrato e parada 

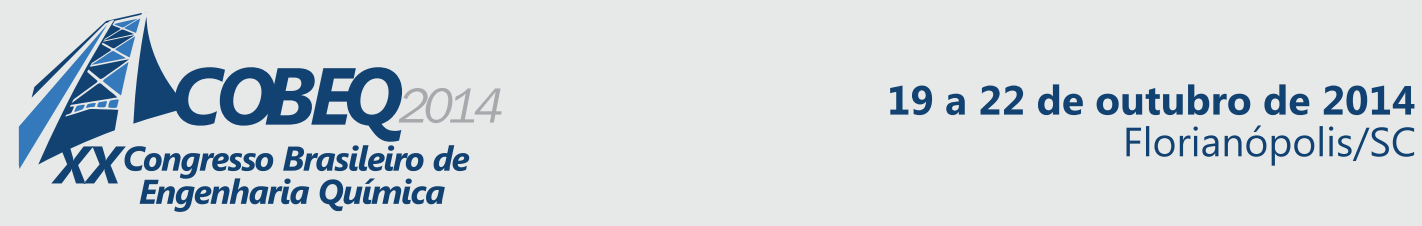

da produção de etanol, sendo a condição empregada de concentração de furfural aquela que mais interferiu no processo fermentativo, atingindo a fase estacionária de crescimento em $48 \mathrm{~h}$ e permanecendo no meio, sem consumo, $30 \%$ da quantidade inicial de xilose. A maior inibição causada pelo furfural à fermentação com xilose está em consonância com a literatura, onde Limayem e Ricke (2012) citam que, durante a degradação dos açúcares nos pré-tratamentos ácidos, há a formação de inibidores como o furfural, oriundo, principalmente, da desidratação das pentoses, e hidroximetilfurfural (HMF), a partir da desidratação das hexoses, além de compostos fenólicos e ácido acético. Estes compostos causam danos ao microrganismo, reduzindo as atividades biológica e enzimática, quebrando o DNA e inibindo a síntese de RNA e proteína (Ra et al., 2013).

A Tabela 1 apresenta as variações de crescimento celular $(\Delta \mathrm{X})$, consumo de substrato $(\Delta \mathrm{S})$ e produção de etanol $(\Delta \mathrm{P})$ após $72 \mathrm{~h}$ de fermentação, bem como os valores encontrados para os parâmetros $\mathrm{Y}_{\mathrm{P} / \mathrm{S}}, \mathrm{Y}_{\mathrm{X} / \mathrm{S}}, \mu_{\max }$ e $\mathrm{Q}_{\mathrm{P}}$ obtidos em cada experimento.

Tabela 1 - Parâmetros cinéticos e de conversão obtidos nos ensaios realizados.

\begin{tabular}{cccccccc}
\hline & $\boldsymbol{\Delta} \mathbf{X}(\mathbf{g} / \mathbf{L})$ & $\boldsymbol{\Delta} \mathbf{S}(\mathbf{g} / \mathbf{L})$ & $\boldsymbol{\Delta} \mathbf{P}(\mathbf{g} / \mathbf{L})$ & $\mathbf{Y}_{\mathbf{X} / \mathbf{S}}(\mathbf{g} / \mathbf{g})$ & $\mathbf{Y}_{\mathbf{P} / \mathbf{S}}(\mathbf{g} / \mathbf{g})$ & $\boldsymbol{\mu}_{\max }\left(\mathbf{h}^{-\mathbf{1}}\right)$ & $\mathbf{Q}_{\mathbf{P}}(\mathbf{g} / \mathbf{L} . \mathbf{h})$ \\
\hline Controle & 2,26 & 11,43 & 6,71 & 0,197 & 0,587 & 0,053 & 0,093 \\
HAc & 1,94 & 9,17 & 4,01 & 0,212 & 0,438 & 0,033 & 0,056 \\
F & 1,63 & 7,00 & 3,54 & 0,233 & 0,505 & 0,040 & 0,049 \\
HMF & 3,54 & 9,26 & 9,24 & 0,383 & 0,998 & 0,048 & 0,192 \\
\hline
\end{tabular}

À exceção do processo fermentativo com adição de HMF, a conversão de xilose em células ( $\mathrm{Y}_{\mathrm{X} / \mathrm{S}}$ ) foi próxima a $0,2 \mathrm{~g} / \mathrm{g}$, com rendimentos próximos ao apresentado na literatura em estudos com adição de glicose e xilose como substratos, sem adição de inibidores (Cabral et al., 2005; Silva et al., 2011; Farias et al., 2012). Para o ensaio sem adição de inibidores (controle) o rendimento da conversão de xilose a etanol foi $0,587 \mathrm{~g} / \mathrm{g}$.

Garcia (2012) cita que fatores como pH, temperatura, aeração, adição de nutrientes e concentrações iniciais de substrato e de inóculo podem influenciar a bioconversão de açúcares a etanol. A composição do meio de cultura, por exemplo, pode não apenas suprir as necessidades nutricionais do microrganismo, como também promover ou aumentar a tolerância da Pichia aos compostos inibidores presentes no hidrolisado. Também, maiores concentrações celulares podem conduzir a maior viabilidade celular e, consequentemente, maior formação de biomassa e produto, tornando-se uma estratégia para amenizar o efeito tóxico dos inibidores (Agbogbo et al., 2007).

A escolha das condições do processo tem efeito direto na resposta metabólica, tornando-se difícil uma única explicação para a resposta fisiológica. García-Cubero et al. (2011), em fermentações com a mistura de glicose e xilose, citam que o consumo de xilose foi inibido em $0,5 \mathrm{~g} / \mathrm{L}$ de $\mathrm{HMF}$, porém com efeito não tão significativo quanto ao das fermentações com os inibidores ácido acético e furfural, enquanto a adição de 0,1 g/L de HMF teve um efeito positivo no crescimento celular, o qual foi ligeiramente maior do que o experimento controle tendo, ao final do processo de fermentação, semelhante produção de etanol. Ask et al. (2013), em cultivo anaeróbio da levedura Saccharomyces 


\section{9 a 22 de outubro de 2014 \\ Florianópolis/SC}

cerevisiae em meio contendo glicose, xilose e 2 g/L de HMF, observaram redução na taxa de consumo de glicose e maiores absorção de xilose e produção de etanol, glicerol e xilitol.

O que ocorreu nos experimentos com HMF e apenas xilose foi um crescimento celular $40 \%$ superior ao ensaio controle, consumo quase que completo do substrato e grande formação de etanol em ambas fermentações com este inibidor. A literatura considera estabelecido o mecanismo de conversão do furfural em álcool furfurílico e indica que, pela estrutura semelhante do HMF e do furfural, pode haver a conversão do HMF em um composto denominado 2,5-bis-hidroximetilfurano, identificado em espectro UV/Vis a $222 \mathrm{~nm}$ (Ra et al., 2013). Assim, há a necessidade de estudos mais detalhados quanto a esta fermentação, seja no que diz respeito à viabilidade celular, utilização da fonte de carbono, realizando estudos com meio sintético, determinação da concentração de HMF e de etanol.

Os valores da determinação da velocidade específica máxima de crescimento $\left(\mu_{\max }\right)$ foram obtidos pelo ajuste linear dos valores experimentais de $\ln \left(\mathrm{X} / \mathrm{X}_{0}\right)$ em função do tempo. As menores taxas de crescimento foram obtidas com a adição de ácido acético $\left(0,033 \mathrm{~h}^{-1}\right)$, enquanto as maiores no processo sem adição de inibidores $\left(0,053 \mathrm{~h}^{-1}\right)$. Estes valores foram inferiores aos obtidos por Farias et al. (2012), comprovando a necessidade de aeração do meio de cultivo ao longo do processo fermentativo.

As produtividades em etanol na presença de ácido acético (HAc) e furfural (F) foram baixas em relação aos experimentos com adição de hidroximetilfurfural (HMF) e sem adição de inibidores, os quais obtiveram valores próximos aos obtidos por García-Cubero et al. (2011).

Os resultados obtidos levam à necessidade de estudos da concentração destes inibidores no caldo extraído do pré-tratamento da biomassa lignocelulósica, em especial no pré-tratamento químico, onde uma maior quantidade destes componentes é gerada, de forma a se conduzir estudos mais específicos sobre a influência da mistura dos inibidores na fermentação etanólica pela levedura Pichia stipitis.

\section{CONCLUSÕES}

A levedura Pichia stipitis se mostrou capaz de crescer na presença isolada dos principais inibidores do pré-tratamento da biomassa lignocelulósica, mas mostrou que a mistura destes componentes é capaz de inibir completamente o processo fermentativo. A presença apenas de hidroximetilfurfural, na concentração de $0,40 \mathrm{~g} / \mathrm{L}$, mostrou efeito positivo na fermentação etanólica, diferente ao obtidos nos experimentos com glicose e xilose, enquanto que a presença de 1,75 g/L de ácido acético promoveu menor taxa de crescimento celular e conversão do substrato xilose em etanol. A presença de $1,25 \mathrm{~g} / \mathrm{L}$ de furfural levou à inibição no crescimento e no consumo de xilose, chegando à fase estacionária após 48 h de fermentação.

\section{AGRADECIMENTOS}

À Embrapa Agroenergia, pelo auxílio à pesquisa e doação da levedura. 


\section{REFERENCIAS}

AGBoGBO, F. K.; WENGER, K. S. Production of ethanol from corn stover hemicellulose hydrolyzate using Pichia stipitis. Journal of Industrial Microbiology and Biotechnology, v. 34, p. 723-727, 2007.

AGBOGBO, F. K.; HAAGENSEN, F. D.; MILAM, D.; WENGER, K. S. Fermentation of acidpretreated corn stover to ethanol without detoxification using Pichia stipitis. Applied Biochemistry and Biotechnology, v. 145, p. 53-58, 2008.

AGÊNCIA NACIONAL DO PETRÓLEO, GÁS NATURAL E BIOCOMBUSTÍVEIS (Brasil). Anuário estatístico brasileiro do petróleo, gás natural e biocombustíveis: 2013. Agência Nacional do Petróleo, Gás Natural e Biocombustíveis - Rio de Janeiro: ANP, 2013

ALMEIDA, J. R. M.; FÁVARO, L. C. L. Leveduras para produção de etanol de sorgo sacarino. Agroenergia em Revista, ed. 3, ago. 2011.

ASK, M.; BETTIGA, M.; MAPELLI, V.; OLSSON, L. The influence of HMF and furfural on redoxbalance and energy-state of xylose-utilizing Saccharomyces cerevisiae. Biotechnology for Biofuels, $\mathrm{v}$. 6, n. 22, p. 1-13, 2013.

BALLESTEROS, M. Estado del desarrollo tecnológico del aprovechamiento de biomasa: biocombustibles para el sector del transporte. Energía, v.161, p. 29-34, 2001.

CABRAL, J.C.A.; SILVA, J.P.A.; ROBERTO, I.C. Influência do pH na produção de etanol por Pichia stipitis. In: Encontro Latino Americano de Pós-Graduação, 9, 2005, Lorena-SP.

DEMIRBAS, A. Bioethanol from cellulosic materials: a renewable motor fuel from biomass. Energy Sources, v. 27, p. 327-337, 2005.

FARIAS, D.; ATALA, D. I. P.; MAUGERI, F. Modelagem cinética da fermentação de xilose por Pichia stipitis. In: XIX Congresso Brasileiro de Engenharia Química. Búzios, RJ, 2012.

FUGITA, T. Desempenho de leveduras que metabolizam xilose para produção de etanol em hidrolisado hemicelulósico de bagaço de cana. 2010. Dissertação (Mestrado em Microbiologia) Universidade Estadual Paulista.

GARCIA, D. Estudo da produção de etanol pela levedura Pichia stipitis a partir do hidrolisado hemicelulósico de bagaço de malte. 2012. Tese (Doutorado em Ciências) - Escola de Engenharia de Lorena - Universidade de São Paulo.

GARCÍA-CUBERO, M. T.; BELLIDO, C.; BOLADO, S.; COCA, M.; LUCAS, S.; GONZÁLEZBENITO, G. Effect of inhibitors formed during wheat straw pretreatment on ethanol fermentation by Pichia stipitis. Bioresource Technology, v. 102, p. 10868-10874, 2011.

LEE, T.Y.; KIM, M. D.; KIM, K. Y.; PARK, K.; RYU, Y. W.; SEO, J. W. A parametric study on ethanol production from xylose by Pichia stipitis. Biotechnology and Bioprocess Engineering, v. 5, p. 27-3, 2000.

LIMAYEM, A.; RICKE, S. C. Lignocellulosic biomass for bioethanol production: Current perspectives, potential issues and future prospects. Progress in Energy and Combustion Science, v. 
38, p. 449-467, 2012

MILLER, G. L., Use of dinitrosalicylic acid reagent for determination of reducing sugar. Analytical Chemistry, v.31, n. 3, p. 426-428, 1959.

MORAES, D. C.; MURARI, C. S.; AQUINO, P. L. M.; BUENO, G. F.; DEL BIANCHI, V. L. Avaliação da fermentação aeróbia para produção de etanol a partir da xilose por linhagens de leveduras isoladas da casca de uva (Vitis spp). Revista Brasileira de Produtos Agroindustriais, v. 15, n. 2, p. 117-122, 2013.

MORAES, D. C.; PEREZ, C. A.; DORTA, C. Seleção de microrganismos fermentadores de xilose. Revista Analytica, ano 8, n. 47, p. 59-67, jun/jul 2010.

NIGAM, J. N., Ethanol production from wheat straw hemicellulose hydrolysate by Pichia stipitis. Journal of Biotechnology, v. 87, p. 17-27, 2001

PEREIRA Jr., N. Biomassas residuais de composição lignocelulósica para a produção de etanol e o contexto de refinaria, 2007.

RA, C. H.; JEONG, G. T.; SHIN, M. K.; KIM, S. K. Biotransformation of 5-hydroxymethylfurfural (HMF) by Scheffersomyces stipitis during ethanol fermentation of hydrolysate of the seaweed Gelidium amansii. Bioresource Technology, v. 140, p. 421-425, 2013.

ROSSELL, C.E.V. Evolução tecnológica da produção de etanol. Expectativas futuras: destilarias otimizadas, etanol da hidrólise de bagaço. In: Reunião Anual da SBPC, 60ª , 2008, Campinas-SP.

SILVA, J. P. A.; MUSSATTO, S. I.; ROBERTO, I. C.; TEIXEIRA, J. A. Ethanol production from xylose by Pichia stipitis NRRL Y-7124 in a stirred tank bioreactor. Brazilian Journal of Chemical Engineering, v. 28, n. 1, p. 151-156, jan-mar 2011.

SUNITHA, K.; LEE, J. K.; OH, T. K. Optimization of medium components for phytase production by E. coli using response surface methodology. Bioprocess Engineering. v. 21, p. 477-481, 1999. 